\title{
Article
}

\section{Sex and age differences in the early identification and treatment of alcohol use: a population-based study of patients with alcoholic cirrhosis}

Otete, Harmony, orton, Elizabeth, Fleming, Kate and West, Joe Available at https://clok.uclan.ac.uk/30239/

Otete, Harmony orcid iconORCID: 0000-0003-2467-2605, orton, Elizabeth, Fleming, Kate and West, Joe (2015) Sex and age differences in the early identification and treatment of alcohol use: a population-based study of patients with alcoholic cirrhosis. Addiction, 110 (12). pp. 1932-1940. ISSN 0965-2140

It is advisable to refer to the publisher's version if you intend to cite from the work. http://dx.doi.org/10.1111/add.13081

For more information about UCLan's research in this area go to http://www.uclan.ac.uk/researchgroups/ and search for <name of research Group>.

For information about Research generally at UCLan please go to http://www.uclan.ac.uk/research/

All outputs in CLoK are protected by Intellectual Property Rights law, including Copyright law. Copyright, IPR and Moral Rights for the works on this site are retained by the individual authors and/or other copyright owners. Terms and conditions for use of this material are defined in the policies page. 


\title{
Alcohol-attributable health care attendances up to 10 years prior to diagnosis of alcoholic cirrhosis: a population based case control study
}

Harmony E Otete ${ }^{1,2}$, Elizabeth Orton ${ }^{3}$, Kate M Fleming ${ }^{1.2}$, Joe West $^{1}$

\author{
Author Affiliation: \\ ${ }^{1}$ Division of Epidemiology and Public health, School of Medicine, City Hospital Campus, University \\ of Nottingham, Nottingham, NG5 1PB, UK \\ ${ }^{2}$ UK Centre for Tobacco and Alcohol Control Studies (UKCTAS), University of Nottingham, \\ Nottingham, NG5 1PB, UK \\ ${ }^{3}$ Division of Primary Care, School of Medicine, University of Nottingham, UK
}

Correspondence: Harmony E Otete, Division of Epidemiology and Public Health, City Hospital campus, University of Nottingham, NG5 1PB, UK.

Fax: +44 (0)115 82 31337; Email: mcxehot@nottingham.ac.uk

Keywords: Alcoholic liver disease, early identification, comorbidities, intervention, healthcare utilisation

Abbreviations: CI, Confidence Interval; OR, Odds ratio; CPRD, Clinical Practice Research Datalink; HES, Hospital Episodes Statistics; ICD, International Classification of Diseases; LRT, likelihood ratio tests; IQR, Interquartile range.

\section{Conflict of interest: None}

Electronic word count: 4,988 (includes abstract, key points, tables, figures and references)

\section{Number of tables: 5}

Financial support: This work was supported by funding from a scholarship awarded to HEO by The University of Nottingham. JW, through his Senior Clinical Research Fellowship, and the UK Centre for Tobacco and Alcohol Studies (UKCTAS) also contribute to HEO's funding. 
Author contributions: KMF and JW conceived the study idea. HEO carried out the data management and analysis and wrote the first draft of the manuscript. All authors (HEO, EO, KMF AND JW) were involved in the interpretation of the data, contributed towards to revision of the manuscript and approved the final draft. JW had the responsibility of providing the data and HEO had full access to the data. 


\section{Abstract \\ Background \& Aims}

Cirrhosis due to alcohol could be avoided if drinking behaviour could be altered earlier in the disease course. Our aim was to quantify the burden of morbidities in patients prior to alcoholic cirrhosis diagnosis, as this may inform the earlier identification of people at high risk for targeted interventions.

\section{Methods}

We carried out a case-control study using 2,479 incident cases of alcoholic cirrhosis and 24,790 controls identified from 357 primary and secondary care centres in England. We assessed the prevalence of morbidities that are partly attributable to alcohol (namely malignant neoplasms, diabetes, epilepsy, injuries, cardiovascular and digestive diseases) prior to alcoholic cirrhosis diagnosis. We compared prevalence in cases to the control population and used logistic regression to derive odds-ratios $(95 \% \mathrm{CI})$.

Results

$58 \%$ of cases compared to $29 \%$ of controls had had at least one alcohol-attributable condition before cirrhosis diagnosis. The most frequent conditions (proportion in cases versus controls) were intentional injuries(35.9\% versus $11.9 \%)$ and cardiovascular diseases(23.2\% versus $15.6 \%)$, followed by diabetes( $12.8 \%$ versus $5.3 \%)$, digestive diseases $(6.1 \%$ versus $1.2 \%)$ and epilepsy(5.0\% versus $1.1 \%)$. The strongest association with alcoholic cirrhosis was found for digestive diseases(OR 5.4 [4.4-6.7]), epilepsy(OR4.4[3.5-5.5]) and injuries (OR 4.0[3.7-4.4]) particularly among those aged 18-44years.

\section{Conclusion}

These data highlight the high burden of other alcohol-attributable conditions in patients prior to alcoholic cirrhosis diagnosis. Reviewing those consistently presenting with any of these conditions more closely could help practitioners reduce/avoid the long term consequences of development of alcoholic liver disease. 


\section{Key points}

- Early identification of people at risk of alcoholic cirrhosis could help limit/reverse the increasing rates of liver disease mortality in the UK.

- We found a high burden of other alcohol-attributable conditions (injuries, seizures, diabetes, cardiovascular and digestive diseases) in patients up to 10 years prior to the diagnosis of alcoholic cirrhosis.

- Injuries, seizures and digestive diseases had the strongest association with subsequent development of alcoholic cirrhosis.

- Physicians could combine these early warning signs of alcohol-related attendances with other important prognostic information to increase their assessment of alcohol misuse and liver disease risk in individuals. 


\section{Introduction}

Alcoholic cirrhosis is one of the major contributors to liver disease morbidity and mortality(1,2). With some variation, it requires around 10-20 years to become fully established(3,4). During this time people are likely to be drinking alcohol heavily(4-7) and therefore likely to present to their family doctor/General Practitioner or to hospital emergency departments for conditions that are related to alcohol, but not necessarily directly related to cirrhosis. This is not dissimilar to the situation where patients persistently present to primary care with smoking related symptoms e.g. weight loss and angina-like chest pain several years before they are diagnosed with lung cancer(8-10). Knowledge of such symptoms that are associated with the cause of a disease, rather than a disease itself, has been used in the past as a proxy for risk stratification of individuals for targeted interventions(11,12). Such stratification could result in improvement in early diagnosis rates and reduction in mortality from chronic diseases which are otherwise extremely problematic both in terms of prognosis and complications if identified at a late stage(13).

For alcoholic cirrhosis however there is lack of information on the likely burden of alcohol related morbidity that may be present in patients before cirrhosis diagnosis. The morbidities believed to be associated with alcohol are many including some malignancies, cardiovascular diseases, epilepsy, unintentional and self-harm injuries, and therefore offer the potential for stratification on a population level(14). Yet, limited studies have explored the occurrence of these morbidities in patients with cirrhosis. We identified one prior small study of 94 people with alcoholic liver disease which reported the occurrence of limited categories of morbidities (injuries, seizures, oral malignancy and digestive diseases) as a secondary study outcome(15) but there was no comparison population in this study and so the significance of reported morbidities remains unclear. 
Given the impact of alcoholic cirrhosis on life expectancy(16) and the potential benefits of preventative interventions, there is a clear need to better understand which morbidities may be present in patients before the disease is diagnosed. The aim of this study therefore was to estimate the burden of diseases that are reported to be at least partly attributable to alcohol in patients during the time leading up to a diagnosis of cirrhosis, in comparison with the general population. 


\section{Methods}

Design and data source

This was a case-control study using primary healthcare data from the Clinical Practice Research Datalink (CPRD), a nationally representative database containing electronic information on consultations and diagnoses delivered in primary care in the United Kingdom; and linked hospital admissions data from the UK's Hospital Episodes Statistics (HES) database.

Data linkage: Primary care records in CPRD have been linked to secondary care records in HES at the individual patient level since 1997; however primary care practices have to give consent before the linkage of patient records can be carried out. At the time of this study, 357 English GP practices that contribute data to CPRD had given consent for linkage to occur. The linkage is undertaken by a trusted third party prior to release for research, using patient's unique ID number, date of birth and gender. Research data are received in fully anonymised form.

Study population

All adult (>18 years) patients from CPRD-HES linked practices diagnosed with alcoholic cirrhosis between 1997 and 2012 were identified. Alcoholic cirrhosis was defined by the presence of a recorded diagnostic code for the disease in either primary or secondary care. The code lists were adapted and updated from our previously validated definition $(17,18)$. We excluded cases with a history of any condition that the differential diagnosis could have been alcoholic cirrhosis (e.g. cirrhosis or oesophageal varices of unspecified aetiology), as this may have introduced potential misclassification of the diagnosis date. We also ensured that cases were at least registered with a practice for up to one year before their first diagnosis 
record to ensure we included only incident cases. From the remaining CPRD-HES linked patients without a history of cirrhosis or oesophageal varices, we selected 10 control patients for each case frequency matched by age (+/- 5 years) and general practice. A date of diagnosis, defined as the date for the first record of alcoholic cirrhosis, was assigned to cases. Controls were assigned a "pseudo-diagnosis" date which was a randomly generated date between 1 year after the start of the linked dataset(1997) up to the date they left the practice or died.

\section{Identifying partly alcohol-attributable morbidity in primary and secondary care}

The conditions considered to be partly attributable to alcohol were based on England's national guide for alcohol-attributable fractions which has been validated against other international sources $(23,24)$. These were oral cancers(ICD-10: C00-C14);oesophageal cancer(C15); colorectal cancers(C18-C21); breast cancer(C50); diabetes mellitus (E10-E14); epilepsy(G40, G41); hypertensive disease(I10-I14);ischaemic heart disease(I20-I25); haemorrhagic stroke(I60-I62);ischaemic stroke(I63);road traffic accidents (many V codes); falls(W00-W19);drowning(W65-W74);poisonings(X40-X49);other unintentional injuries (rest of V codes plus some W, X, Y codes);self-inflicted injuries(X60-X84, Y87.0); violence (X85-Y09, Y87.1); and other intentional injuries(Y35). Read and ICD 10 codes for these conditions were used to examine the records of all patients to identify people with these diagnoses before cirrhosis diagnosis/pseudo-diagnosis. Where a patient had multiple consultations or hospital admissions with a specific diagnostic code, only the first record was kept for our analyses. Where codes for different diseases were first entered on the same date for example if an individual received a diagnosis code for hypertension and was also diagnosed with diabetes on the same date, both records of unique diseases were included. We grouped each first diagnosis into four exposure periods: within 12 months, between 13 months-2 years, between 3-5 years and between 6-10 years pre-diagnosis or pseudo- 
diagnosis. For clarity of presentation we further grouped all diseases into categories(malignant neoplasms, diabetes, diseases of the nervous system, cardiovascular diseases, digestive diseases, and injuries) based on ICD10 chapter headings.

\section{Covariates}

We extracted data on patient sex, age, smoking history and alcohol use from CPRD. Age was calculated as age at alcoholic cirrhosis diagnosis/pseudo-diagnosis and grouped into five age bands. The most recent smoking record before diagnosis/pseudo-diagnosis was used to classify individuals as non-smoker, smoker or ex-smoker. The highest level of recorded alcohol use was used to classify individuals as never, moderate or harmful or hazardous drinker. Patients with an alcohol record that did not specify consumption frequency and volume e.g. "beer drinker", "wine drinker" were assigned as having an "unclear" alcohol consumption status. Missing data on smoking or alcohol use was addressed by including a "no recorded data" category so that such patients were not excluded from the analyses.

\section{Statistical analysis}

We calculated the proportion of patients ever diagnosed with any alcohol-attributable condition listed above. Logistic regression was used to explore the association between each ICD category and alcoholic cirrhosis. We tested for effect modification by age and sex via stratified analyses and the fitting of interaction terms in our logistic regression model; the significance of models was tested using likelihood ratio tests(LRTs), with $\mathrm{p}<0.05$ considered significant. 
To investigate whether the occurrence of each condition varied across the pre-diagnosis period, frequencies and odds ratios were recalculated for each condition for the four predefined pre-diagnosis exposure periods. Not all patients were included in this analysis. We applied restriction based on completeness of follow up such that the analyses for any time period were limited to those with complete follow up. For example, only patients with a minimum of 2 years' worth of pre-diagnosis data were included in 13 months-2 year time period analyses and only those with up to 5 years' worth of data were included in the 3-5 year period. Additional analysis was carried out on injuries to take into account that injuries are acute and therefore people could have multiple acute injuries over time. For this analysis, we considered whether a patient had had any new injury in each time period rather than just in the period of their first injury and reassessed frequencies and odds ratios using this additional information.

All analyses were conducted using the statistical software Stata v12.0 (StataCorp, Texas).

\section{Ethics statement}

Ethical approval for this study was granted from the Independent Scientific Advisory Committee of the CPRD (15_073R). 


\section{Results}

A total of 2,479 cases and 24,790 controls were included in the study. The mean age at cirrhosis diagnosis was 55.6 years. The median observation time prior to diagnosis/pseudo diagnosis was higher in cases than controls: 5.7 years(IQR 3.0-9.2 years) and 4.6 years(IQR 2.4-7.9 years) respectively. Compared with controls, cases were more likely to be men, current smokers and harmful/hazardous drinkers (Table 1).

As shown in table 2, nearly two-thirds (58\%) of cases had presented with at least one condition partially attributable to alcohol during a preceding primary care or hospital visit, compared to $29 \%$ in the control population. Compared to the control population, we found a stronger risk of alcoholic cirrhosis in those cases with three or more morbidities(OR 9.3,95\% CI [7.5-11.7]) than in those with one morbidity(OR 2.7,95\%CI[2.5-3.0]). When we compared cirrhosis risks across age groups, we found stronger associations with cirrhosis for younger patients(OR for those $<45$ years $6.1,95 \% \mathrm{CI}[4.9-7.5]$ ) who had presented with an attributable morbidity compared to older patients(OR for those >75years 2.5, 95\%CI[1.7-3.7]). Comparing risks by sex, no substantial difference was observed between men and women.

Table 3 shows age stratified proportions and ORs for each disease group. The most common conditions among cases were injuries(35.9\%), cardiovascular diseases(23.2\%) and diabetes (12.8) corresponding to adjusted odds ratios of 4.0(95\% CI[3.7-4.4]), 1.6 (95\% CI[1.5-1.8]) and 2.5 (95\%CI[2.2-2.9]) (Table 3). Digestive(6.1\%) and nervous system(5.0\%) diseases were relatively uncommon but had the highest odds ratios when comparing cases to controls at $5.4(95 \% \mathrm{CI}[4.4-6.7])$ and $4.4(95 \% \mathrm{CI}[3.5-5.5])$ respectively. We observed a marked variation in the magnitude of effect across age groups for most diseases. The odds of cardiovascular, nervous system, digestive diseases and injuries for instance generally decreased with increasing age, with the highest odds among those aged less than 45 years old. 
For malignant neoplasms and diabetes, odds were highest for those less than 45 years and for those over 75 years compared to the other age groups.

When proportions were calculated for the individual conditions within each ICD 10 category (Table 4), we observed that within each category, certain conditions were more strongly associated with subsequent diagnosis of alcoholic cirrhosis than others. For example, within the cardiovascular disease category, cardiac arrhythmias had the strongest association with alcoholic cirrhosis (Adjusted OR 4.2,95\% CI[3.3-5.6]) compared to hypertension(adjusted OR 1.5, 95\%CI[1.3-1.7]) or cerebrovascular diseases (adjusted OR 1.8,95\% CI[1.4-2.3]). Among injuries, intentional injuries and self-harm (Adjusted OR 6.6, 95\%CI[5.4-7.9]) were more strongly associated with subsequent diagnosis with alcoholic cirrhosis than unintentional injuries(OR 3.7, 95\% CI [3.4-4.1]) (Table 4).

Table 5 shows proportions and ORs for assessed conditions at different time periods. There were variations in the odds of the various conditions over time with some conditions increasing and others decreasing. Digestive diseases and diabetes were more likely to occur around cirrhosis diagnosis than at other times. ORs for cardiovascular diseases did not change markedly throughout the entire 10 year window but were slightly higher in the 6-10 year period than in earlier periods. Epilepsy and intentional injuries had relatively high ORs which persisted strongly throughout the entire 10 year period assessed. Reanalysing injuries showed a stronger association between both intentional and unintentional injuries and alcoholic cirrhosis particularly in the 3-5year time periods but did not markedly change the overall time-specific patterns. 


\section{Discussion}

We have found that compared with patients in the general population, those patients who acquire a diagnosis of alcoholic cirrhosis attend both primary and secondary health care providers more frequently with other conditions reported to be attributable to alcohol as far back as 10 years before the diagnosis of alcoholic cirrhosis. The conditions with the highest frequency in cases were injuries(unintentional), cardiovascular diseases (hypertension in particular), and diabetes. However, these did not appear to be particularly specific to alcoholic cirrhosis as they were also reasonably prevalent among the control population. Digestive diseases, intentional injuries and epilepsy which were relatively uncommon among cases, appeared to be more strongly associated with alcoholic cirrhosis. It could therefore be argued that while targeting individuals with any alcohol-attributable disease may be beneficial, focussing on those who present with any of these three conditions (digestive diseases, intentional injuries and epilepsy) may be a more sensitive way of identifying people who will be more likely to develop alcoholic cirrhosis of the liver later on.

The main strengths of our study are its large study size and that the morbidities we have assessed were prospectively recorded in routinely collected data before the diagnosis of alcoholic cirrhosis, thus avoiding recall bias. We frequency-matched cases and controls on general practice and age to account for differences in data recording between practices and differences in healthcare seeking behaviour between age groups respectively, but which also allowed us to assess interaction by age where it occurred. Data held in CPRD are generally representative of the UK population in terms of age, sex and geographical coverage(19). However, because HES contains admission information for only English hospitals, CPRD patients from Wales, Scotland and Northern Ireland were excluded. Our results are therefore expected to be generalizable to the English population at the very least. 
Some limitations of our study and potential alternative explanations for our findings should be noted. First, although we have accounted for age differences in healthcare seeking behaviour, there are other potential modifiers of this that we were unable to adjust for e.g. socio-economic status, education and family history. We therefore cannot rule out the possibility of residual confounding on our estimates. We have intentionally not adjusted our estimates for level of alcohol use since alcohol consumption is directly on the causal pathway of alcoholic cirrhosis and thus adjustment would be inappropriate.

The morbidities we have assessed were prospectively recorded in the medical record before the diagnosis of alcoholic cirrhosis. However there is still the possibility of reverse causality, particularly in the association between diabetes and cirrhosis that we observed. Several studies have shown that metabolic syndrome related to pre-existing diabetes may result in an increased predisposition to cirrhosis(20-22). Alternatively, it has also been implied that impaired glucose metabolism in cirrhosis can lead to diabetes(23-25). Since, as with all epidemiological studies of chronic diseases with long subclinical periods (i.e. both diabetes and cirrhosis), we are only able identify the date of acquisition of cirrhosis (or diabetes) diagnosis rather than the date of biological onset, it becomes difficult to definitively establish the temporal association of the relationship.

The exceptionally high risk of digestive diseases and diabetes we found within the year of cirrhosis diagnosis compared to other later periods may reflect another potential problem, namely ascertainment bias. This may occur during gastro-intestinal based work-up for cirrhosis diagnosis where clinical suspicion of liver disease was high in the year prior to diagnosis of alcoholic cirrhosis. However, it could also be argued that perhaps the presence of other digestive diseases may have led to quicker diagnosis of alcoholic cirrhosis, since those with these morbidities would have been more likely to utilise healthcare services leading to increased opportunities to identify cirrhosis. 
Finally, we have shown a higher risk of several malignancies (oropharynx, oesophageal and laryngeal cancers) among people with alcoholic cirrhosis. A common factor that is also strongly associated with these malignancies is cigarette smoking(26,27). Since nearly half of the cases included in our study were identified as smokers, it is likely that the higher risk of laryngeal and oesophageal cancer we have found may well be related more importantly to smoking and only partly to alcohol. Though we have adjusted for most recent documented smoking status this is probably an imperfect measurement of true lifetime smoking habit (e.g. we are unable to adjust for pack-years as this level of detail is not available in our data) and there will likely be residual confounding by smoking in operation in our adjusted effect estimates.

\section{Previous literature}

There are limited studies published on healthcare use and morbidities in people with alcoholic cirrhosis with which we can compare our study. Verrill et al (2006) retrospectively reviewed hospitalised patients with alcoholic cirrhosis in Southampton, UK between 1995 and 2000 to identify how often patients had made contact with primary or secondary care in the five year period before they received a diagnosis of alcoholic cirrhosis. Similar to our findings, they report that patients had presented with injuries, seizures, oral cancers and digestive diseases during the period before alcoholic cirrhosis was diagnosed(15). However, the inclusion of only hospitalised patients who may not be representative of the entire population of people with alcoholic cirrhosis and the absence of any control population make it difficult to directly compare this study with ours. In a second study in Scotland UK where high healthcare utilisation of patients with alcohol use disorders including alcoholic liver 
disease has been shown, morbidities that patients presented with before the disease were not reported(28).

\section{Conclusion and implications}

We believe that the partly alcohol-attributable diseases that patients consult for can be useful as an indication of potential development of alcoholic cirrhosis. We therefore think that physicians could combine the early warning signs of these partially alcohol-attributable diseases and injuries with other important prognostic information to increase their assessment of alcohol misuse in individuals. Particular attention should also be paid to those diagnosed with more than one partially alcohol attributable morbidity as the likelihood of a subsequent diagnosis of alcoholic cirrhosis was 9-fold higher for patients with three or more of these identified morbidities. The stronger associations found between all diseases and cirrhosis for those less than 45 years of age suggests that the potential advantage of risk stratification using alcohol-attributable health care attendances may be even greater in this age group.

In conclusion, we have shown that among most of the patients diagnosed with alcoholic cirrhosis, prior primary or secondary care diagnoses for conditions known to be attributable to alcohol are common. These findings suggest that practitioners may be able to identify those who may later develop alcoholic cirrhosis of the liver by reviewing people presenting with partially alcohol-attributable conditions more closely. We believe that if these high risk groups of patients can be screened for alcohol misuse, and treated appropriately, practitioners may be able to help reduce or avoid the long term consequences of development of alcoholic liver disease. 


\section{References}

1. Rehm J,Samokhvalov AV, Shield KD. Global burden of alcoholic liver diseases. Journal of Hepatology 2013;59:160-8

2. Williams R,Aspinall R, Bellis M,Camps-Walsh G, Cramp M,Dhawan A, et al. Addressing liver disease in the UK: a blueprint for attaining excellence in health care and reducing premature mortality from lifestyle issues of excess consumption of alcohol, obesity, and viral hepatitis. The Lancet. 2014; 384(9958):1953-97.

3. Kamper-Jørgensen M, Grønbæk M, Tolstrup J, Becker U. Alcohol and cirrhosis: doseresponse or threshold effect? Journal of Hepatology. 2004; 41(1):25-30.

4. Becker U, Deis A,Sorensen TI,Gronbaek M,Borch-Johnsen K,Muller CF, et al. Prediction of risk of liver disease by alcohol intake, sex, and age: A prospective population study. Journal of Hepatology. 1996;23(5):1025-9.

5. Verrill C, Markham H,Templeton A,Carr NJ,Sheron N. Alcohol-related cirrhosis-early abstinence is a key factor in prognosis, even in the most severe cases. Addiction. 2009;104(5):768-74.

6. Huang Y-W,Yang S-S,Kao J-H. Pathogenesis and management of alcoholic liver cirrhosis: a review. Hepatic Med Evid Res. 2011;3:1-11.

7. Bellentani S,Saccoccio G,Costa G,Tiribelli C,Manenti F,Sodde M, et al. Drinking habits as cofactors of risk for alcohol induced liver damage. Gut. 1997;41(6):845-50.

8. Hubbard RB,Baldwin DR. Diagnosing lung cancer earlier in the UK. Thorax. 2010 ;65(9):756-8.

9. Corner J,Hopkinson J,Fitzsimmons D,Barclay S,Muers M. Is late diagnosis of lung cancer inevitable? Interview study of patients' recollections of symptoms before diagnosis. Thorax. 2005;60(4):314-9.

10. Hamilton W. Cancer diagnosis in primary care. British Journal of General Practice. 2010;60(571):121-8.

11. Georghiou T,Steventon A,Billings J,Blunt I,Lewis G,Bardsley M. Predictive risk and health care: an overview. [Internet]. London: Nuffield Trust, 2011; Available from: http://www.nuffieldtrust.org.uk/publications/predictive-risk-and-health-care-overview

12. Dixon J,Bardsley M.Predictive risk modelling using routine data: underexploited potential to benefit patients. J Health Serv Res Policy. 2012;17(3):131-2.

13. NHS-Leeds North Clinical Commissioning Group. Risk Stratification (Pro-Active Care Management). 2015. NHS 2015

14. Rehm J,Baliunas D,Borges GLG,Graham K, Irving H, Kehoe T, et al. The relation between different dimensions of alcohol consumption and burden of disease: an overview. Addiction. 2010;105(5):817-43. 
15. Verrill C,Smith S,Sheron N. Are the opportunities to prevent alcohol related liver deaths in the UK in primary or secondary care? A retrospective clinical review and prospective interview study. Subst Abuse Treat, Prev Policy. 2006;1(1):1-5.

16. Ratib S,Fleming KM,Crooks CJ,Aithal GP,West J. 1 and 5 year survival estimates for people with cirrhosis of the liver in England, 1998-2009: a large population study. Journal of Hepatology. 2014;60(2):282-9.

17. Ratib S,West J,Crooks CJ,Fleming KM. Diagnosis of Liver Cirrhosis in England, a Cohort Study, 1998-2009: A Comparison with Cancer. American Journal of Gastroenterology. 2014;109(2):190-8.

18. Fleming KM,Aithal GP,Solaymani-Dodaran M,Card TR,West J. Incidence and prevalence of cirrhosis in the United Kingdom, 1992-2001: A general population-based study. Journal of Hepatology. 11;49(5):732-8.

19. Crooks CJ. Epidemiology of upper gastrointestinal bleeding. Ph.D. Thesis. University Of Nottingham: UK; 2013.

20. Adams LA,Sanderson S,Lindor KD,Angulo P. The histological course of nonalcoholic fatty liver disease: a longitudinal study of 103 patients with sequential liver biopsies. Journal of Hepatology. 2005;42(1):132-8.

21. Angulo P, Keach JC,Batts KP,Lindor KD.Independent predictors of liver fibrosis in patients with nonalcoholic steatohepatitis.Hepatology.1999;30(6):1356-62.

22. Hickman IJ,Macdonald GA. Impact of Diabetes on the Severity of Liver Disease. American Journal of Medicine. 2007;120(10):829-34.

23. Petrides AS. Hepatogenic diabetes: pathophysiology, therapeutic options and prognosis. Z Gastroenterol. 1999 ;Suppl 1:15-21.

24. Deschenes M,Somberg KA. Effect of transjugular intrahepatic portosystemic shunt (TIPS) on glycemic control in cirrhotic patients with diabetes mellitus. American Journal of Gastroenterology. 1998;93(3)483.

25. Picardi A,D'Avola D,Gentilucci UV,Galati G, Fiori E, Spataro S, et al. Diabetes in chronic liver disease: from old concepts to new evidence. Diabetes Metab Res Rev. 2006;22(4):274-83.

26. Gandini S,Botteri E,Iodice S,Boniol M,Lowenfels AB,Maisonneuve P, et al. Tobacco smoking and cancer: a meta-analysis. International Journal of Cancer. 2008 ;122(1):155-64.

27. Dossus L,Boutron-Ruault M-C,Kaaks R,Gram IT,Vilier A,Fervers B, et al. Active and passive cigarette smoking and breast cancer risk: results from the EPIC cohort. International Journal of Cancer. 2014;134(8):1871-88.

28. Morris M,Johnson D,Morrison DS. Opportunities for prevention of alcohol-related death in primary care: results from a population-based cross-sectional study. Alcohol 2012;46(7):703-7. 
Table 1: Study population characteristics.

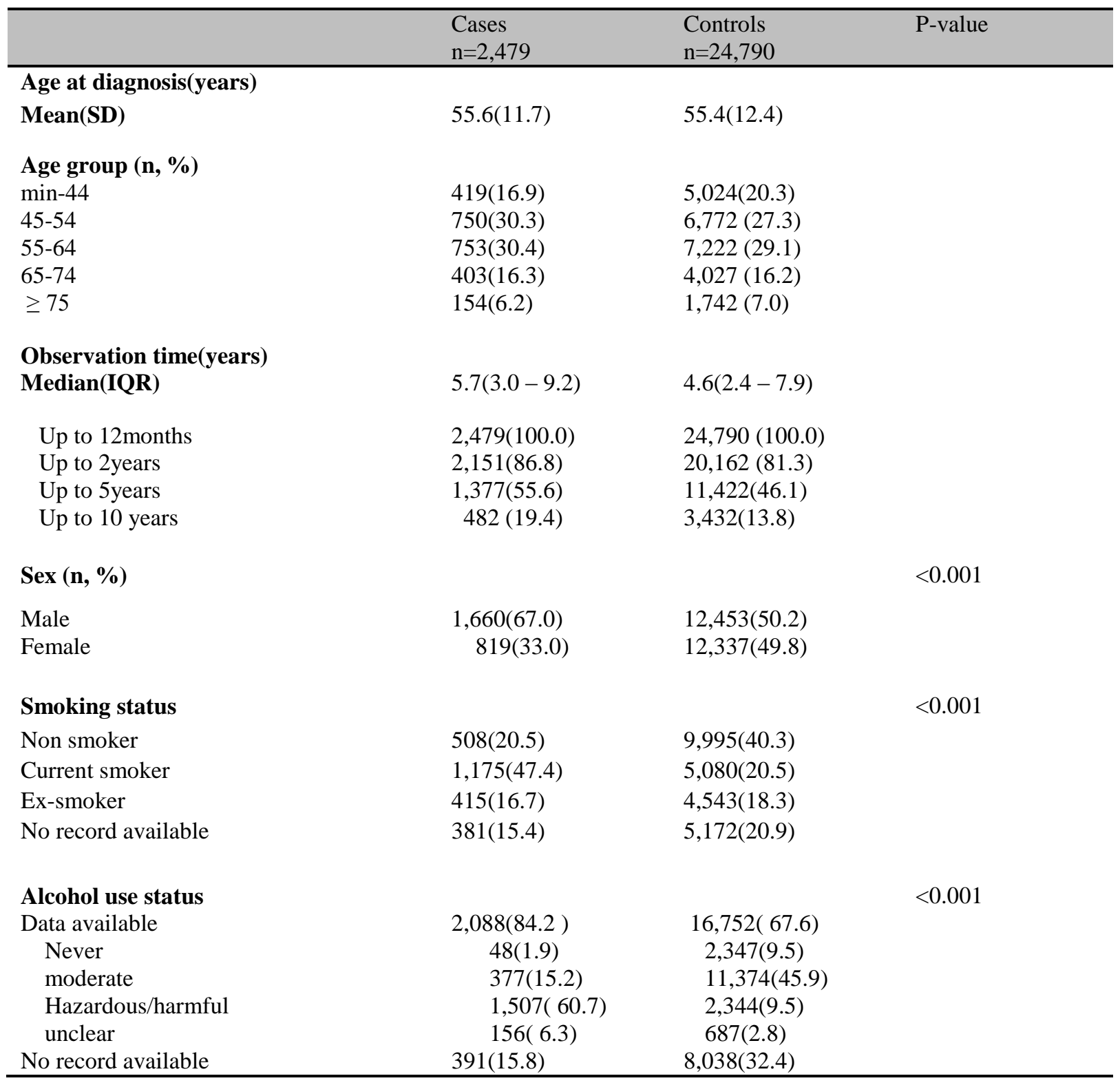


Table 2: Number, proportion and odds ratios describing the likelihood of presenting with at least one partially alcohol-attributable condition at any point during the study

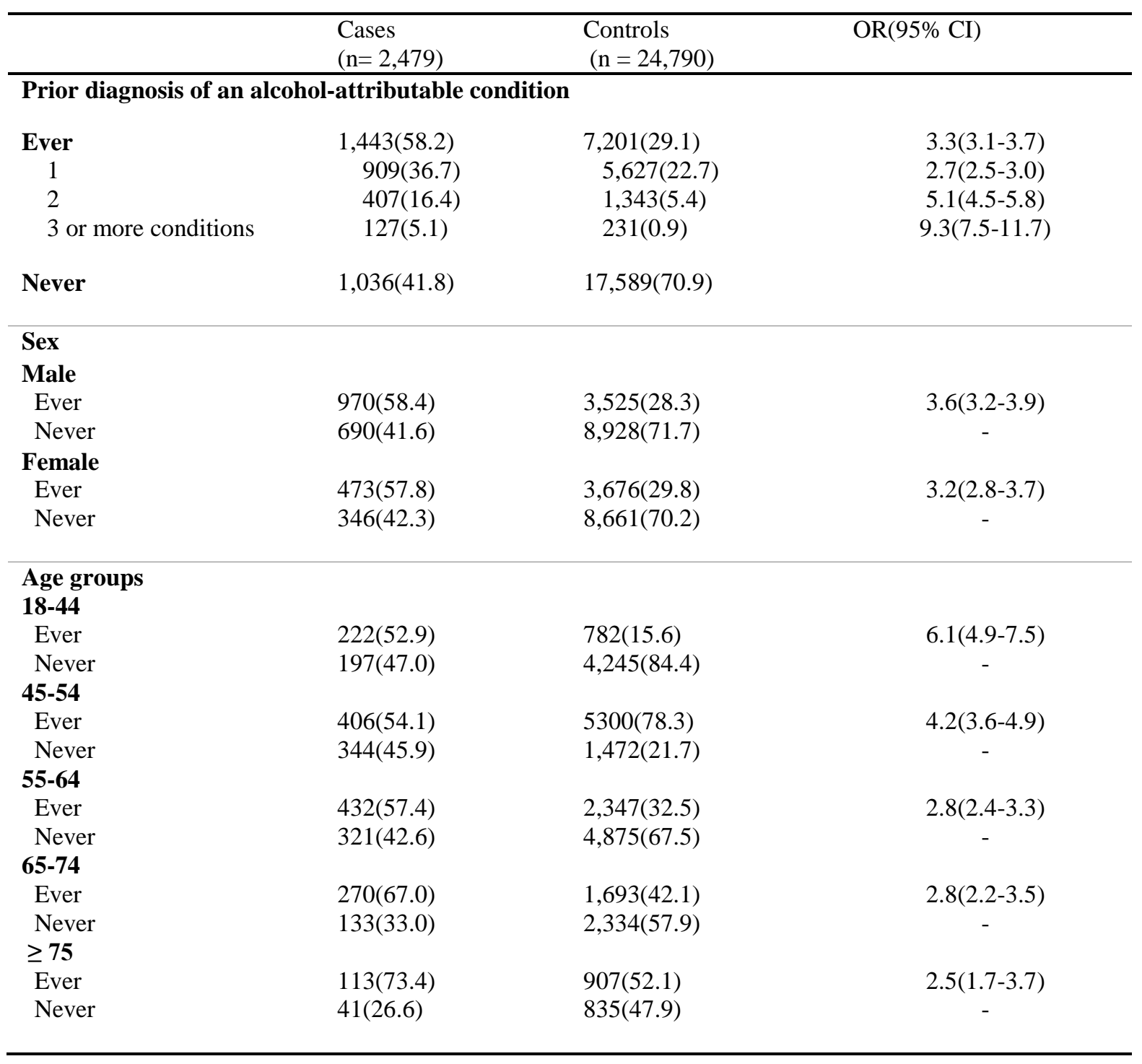

*percentages are calculated as a fraction of those with alcohol attributable conditions, cases $n=1,443$ and controls $\mathrm{n}=7,201$.

Lrtest $P$ value for sex interaction: $\mathrm{p}=0.26$

Lrtest $P$ value for age interaction: $\mathrm{p}<0.0001$ 
Table 3: Overall and age stratified proportions and odds ratios for selected comorbidities( classified by ICD-10 headings) for cases and controls

\begin{tabular}{|c|c|c|c|c|c|}
\hline & \multirow{2}{*}{$\begin{array}{l}\text { Cases } \\
(\mathrm{n}=2,479) \\
\mathrm{n}(\%)\end{array}$} & \multirow{2}{*}{$\begin{array}{l}\text { Controls } \\
(\mathrm{n}=24,790) \\
\mathrm{n}(\%)\end{array}$} & \multicolumn{2}{|c|}{ OR $(95 \% \mathrm{CI})$} & \multirow{2}{*}{$\begin{array}{l}\text { LRT p- } \\
\text { value for } \\
\text { age } \\
\text { interaction }\end{array}$} \\
\hline & & & Unadjusted & Adjusted* & \\
\hline Malignant neoplasms & $62(2.5)$ & 323(1.3) & $1.9(1.5-2.6)$ & 2.4(1.8-3.3) & 0.61 \\
\hline $18-44$ & $4(0.9)$ & $13(0.3)$ & $3.7(1.2-11.5)$ & $4.3(1.3-14.3)$ & \\
\hline $45-54$ & $8(1.1)$ & $47(0.7)$ & $1.5(0.7-3.2)$ & $1.8(0.8-4.0)$ & \\
\hline $55-64$ & $21(2.8)$ & $112(1.6)$ & $1.8(1.1-2.9)$ & $2.4(1.5-3.9)$ & \\
\hline $65-74$ & $17(4.2)$ & $102(2.5)$ & $1.7(1.0-2.9)$ & $2.0(1.2-3.5)$ & \\
\hline$\geq 75$ & $12(7.8)$ & $49(2.8)$ & $2.9(1.5-5.6)$ & $3.3(1.6-6.5)$ & \\
\hline Diabetes & 318(12.8) & $1,303(5.3)$ & 2.7(2.3-2.9) & $2.5(2.2-2.9)$ & 0.02 \\
\hline $18-44$ & $21(5.0)$ & $65(1.3)$ & $4.0(2.4-6.7)$ & $4.0(2.3-6.8)$ & \\
\hline $45-54$ & $62(8.3)$ & $234(3.5)$ & $2.5(1.9-3.4)$ & $2.3(1.7-3.2)$ & \\
\hline $55-64$ & $109(14.5)$ & $445(6.2)$ & $2.6(2.1-3.2)$ & $2.4(1.9-3.1)$ & \\
\hline $65-74$ & $75(18.6)$ & $383(9.5)$ & $2.2(1.7-2.9)$ & $2.0(1.5-2.7)$ & \\
\hline$\geq 75$ & $51(33.1)$ & $176(10.1)$ & $4.4(3.0-6.4)$ & $4.2(2.8-6.3)$ & \\
\hline $\begin{array}{l}\text { Nervous system } \\
\text { diseases }\end{array}$ & $125(5.0)$ & 264(1.1) & 4.9(3.9-6.1) & $4.4(3.5-5.5)$ & 0.0001 \\
\hline $18-44$ & $43(10.3)$ & $53(1.1)$ & $10.7(7.1-16.3)$ & $9.1(5.8-14.3)$ & \\
\hline $45-54$ & $45(6.0)$ & $72(1.0)$ & $5.9(4.1-8.7)$ & $5.1(3.4-7.7)$ & \\
\hline $55-64$ & $27(3.6)$ & $82(1.1)$ & $3.2(2.1-5.0)$ & $3.2(2.0-5.0)$ & \\
\hline $65-74$ & $9(2.2)$ & $33(0.8)$ & $2.8(1.3-5.8)$ & $2.2(1.0-4.7)$ & \\
\hline$\geq 75$ & $1(0.7)$ & $24(1.4)$ & $0.5(0.1-3.4)$ & $0.5(0.1-3.5)$ & \\
\hline $\begin{array}{l}\text { Cardiovascular } \\
\text { diseases }\end{array}$ & $576(23.2)$ & $3,877(15.6)$ & $1.6(1.5-1.8)$ & $1.6(1.5-1.8)$ & 0.0002 \\
\hline $18-44$ & $36(8.6)$ & $151(3.0)$ & $3.0(2.1-4.4)$ & $3.3(2.2-4.9)$ & \\
\hline $45-54$ & $133(17.7)$ & $605(8.9)$ & $2.2(1.8-2.7)$ & $2.1(1.7-2.6)$ & \\
\hline $55-64$ & $194(25.8)$ & $1,353(18.7)$ & $1.5(1.3-1.8)$ & $1.4(1.2-1.7)$ & \\
\hline $65-74$ & $155(38.5)$ & $1,149(28.5)$ & $1.6(1.3-1.9)$ & $1.5(1.2-1.8)$ & \\
\hline$\geq 75$ & $58(37.7)$ & $619(35.5)$ & $1.1(0.8-1.5)$ & $1.1(0.7-1.5)$ & \\
\hline Digestive diseases & $152(6.1)$ & $298(1.2)$ & 5.4(4.3-6.5) & 5.4(4.4-6.7) & $<0.0001$ \\
\hline $18-44$ & $36(8.6)$ & $27(0.5)$ & $17.4(10.4-28.9)$ & $21.1(12.1-36.7)$ & \\
\hline $45-54$ & $35(4.7)$ & $62(0.9)$ & $5.3(3.5-8.1)$ & $5.1(3.2-8.1)$ & \\
\hline $55-64$ & $41(5.4)$ & $101(1.4)$ & $4.1(2.8-5.9)$ & $4.1(2.7-6.0)$ & \\
\hline $65-74$ & $29(7.2)$ & $76(1.9)$ & $4.0(2.6-6.3)$ & $4.1(2.6-6.5)$ & \\
\hline$\geq 75$ & $11(7.1)$ & $32(1.8)$ & $4.1(2.0-8.3)$ & $3.7(1.7-7.7)$ & \\
\hline Injuries & 891(35.9) & 2,962(11.9) & $4.1(3.8-4.5)$ & $4.0(3.7-4.4)$ & 0.008 \\
\hline $18-44$ & $172(41.1)$ & $554(11.0)$ & $5.6(4.5-7.0)$ & $4.9(3.9-6.1)$ & \\
\hline $45-54$ & $270(36.0)$ & $720(10.6)$ & $4.7(4.0-5.6)$ & $4.3(3.5-5.1)$ & \\
\hline $55-64$ & $237(31.5)$ & $835(11.6)$ & $3.5(3.0-4.2)$ & $3.5(2.9-4.2)$ & \\
\hline $65-74$ & $149(36.9)$ & $500(12.4)$ & $4.1(3.3-5.2)$ & $4.3(3.4-5.4)$ & \\
\hline$\geq 75$ & $63(40.9)$ & $353(20.3)$ & $2.7(1.9-3.8)$ & $3.2(2.2-4.6)$ & \\
\hline
\end{tabular}

*adjustment for sex and smoking status 
Table 4: Proportions and ORs for all morbidities for cases and controls

\begin{tabular}{|c|c|c|c|c|}
\hline \multirow[t]{2}{*}{ Conditions } & \multirow{2}{*}{$\begin{array}{l}\text { Cases } \\
(\mathrm{n}=2479)\end{array}$} & \multirow{2}{*}{$\begin{array}{l}\text { Controls } \\
(\mathrm{n}=24,790)\end{array}$} & \multicolumn{2}{|c|}{ OR $(95 \% \mathrm{CI})$} \\
\hline & & & Unadjusted & Adjusted $^{\mathrm{a}}$ \\
\hline \multicolumn{5}{|l|}{ Malignant neoplasms of: } \\
\hline larynx & $5(0.2)$ & $6(0.02)$ & $8.3(2.5-27.4)$ & $6.8(1.9-23.5)$ \\
\hline Colon and rectum & $11(0.4)$ & $82(0.3)$ & $1.3(0.7-2.5)$ & $1.3(0.7-2.5)$ \\
\hline Breast & $12(0.48)$ & 212(0.9) & $0.6(0.3-1.0)$ & $0.9(0.5-1.6)$ \\
\hline Oesophagus & $4(0.2)$ & $12(0.1)$ & $3.3(1.1-10.4)$ & $3.5(1.1-11.3)$ \\
\hline Lip, oral cavity and pharynx & $7(0.3)$ & $18(0.1)$ & $3.9(1.6-9.3)$ & $2.6(1.0-6.4)$ \\
\hline Diabetes $^{b}$ & $318(12.8)$ & $1,303(5.3)$ & $2.6(2.3-3.0)$ & $2.6(2.2-2.9)$ \\
\hline \multicolumn{5}{|l|}{ Diseases of the nervous system } \\
\hline Epilepsy and Status epilepticus & $125(5.0)$ & 264(1.1) & $4.9(3.9-6.1)$ & $4.4(3.5-5.5)$ \\
\hline \multicolumn{5}{|l|}{ Cardiovascular diseases } \\
\hline Cardiac arrhythmias & $84(3.4)$ & $220(0.9)$ & $3.9(3.0-5.1)$ & $4.2(3.3-5.6)$ \\
\hline Cerebrovascular diseases & $96(3.8)$ & $468(1.9)$ & $2.1(1.7-2.6)$ & $1.8(1.4-2.3)$ \\
\hline Hypertensive diseases & $359(14.5)$ & $2,605(10.5)$ & $1.4(1.3-1.6)$ & $1.5(1.3-1.7)$ \\
\hline Ischaemic heart disease & $160(6.5)$ & $1,161(4.6)$ & $1.4(1.2-1.7)$ & $1.2(0.9-1.4)$ \\
\hline \multicolumn{5}{|l|}{ Digestive diseases } \\
\hline Pancreatitis & $83(3.4)$ & $49(0.2)$ & $17.5(12.2-25.0)$ & $15.4(10.6-22.5)$ \\
\hline Cholelithiasis & $81(3.3)$ & 271(1.1) & $3.1(2.4-3.9)$ & $3.1(2.4-4.1)$ \\
\hline \multicolumn{5}{|l|}{ Injuries } \\
\hline Unintentional injuries $^{\mathrm{c}}$ & $790(31.8)$ & $2,752(11.1)$ & $3.7(3.4-4.1)$ & $3.7(3.4-4.1)$ \\
\hline Intentional injury/self-harm ${ }^{\mathrm{d}}$ & $236(9.5)$ & $319(1.3)$ & $8.1(6.8-9.6)$ & $6.5(5.4-7.8)$ \\
\hline
\end{tabular}

\footnotetext{
${ }^{a}$ adjustment for age, sex and smoking status ${ }^{b}$ excludes gestational diabetes ${ }^{c}$ Unintentional injuries include falls, fractures, asphyxia, road traffic accidents and unintentional poisonings.

${ }^{\mathrm{d} I n t e n t i o n a l ~ i n j u r i e s ~ i n c l u d e ~ a s s a u l t, ~ i n t e n t i o n a l ~ s e l f-h a r m ~ a n d ~ i n t e n t i o n a l ~ p o i s o n i n g ~}$
} 
Table 5: The proportion of patients presenting with each examined condition at different periods before cirrhosis diagnosis with $\mathrm{OR}(95 \% \mathrm{CI})$ comparing cases to controls.

\begin{tabular}{|c|c|c|c|c|}
\hline \multirow[t]{2}{*}{ Time to diagnosis } & \multirow{2}{*}{$\begin{array}{l}\text { At risk } \\
\text { cases } \\
\mathrm{n}(\%)\end{array}$} & \multirow{2}{*}{$\begin{array}{l}\text { At risk } \\
\text { controls } \\
\mathrm{n}(\%)\end{array}$} & \multicolumn{2}{|c|}{ OR $(95 \% \mathrm{CI})$} \\
\hline & & & Unadjusted & Adjusted* \\
\hline \multicolumn{5}{|l|}{ Malignant neoplasms } \\
\hline $0-12$ months & $38(1.5)$ & $83(0.3)$ & $4.6(3.1-6.8)$ & $5.1(3.4-7.8)$ \\
\hline $13 \mathrm{mths}-2 \mathrm{yrs}$ & $9(0.4)$ & $61(0.3)$ & $1.4(0.7-2.8)$ & $1.9(0.9-3.9)$ \\
\hline $3-5 y r s$ & $11(0.8)$ & $68(0.6)$ & $1.3(0.7-2.5)$ & $1.6(0.8-3.1)$ \\
\hline $6-10 y r s$ & - & $40(1.2)$ & - & - \\
\hline \multicolumn{5}{|l|}{ Diabetes } \\
\hline $0-12$ months & $78(3.2)$ & $207(0.8)$ & $3.8(2.9-5.0)$ & $3.9(2.9-5.1)$ \\
\hline $13 \mathrm{mths}-2 \mathrm{yrs}$ & $52(2.4)$ & $183(0.9)$ & $2.7(1.9-3.7)$ & $2.3(1.7-3.2)$ \\
\hline $3-5 y r s$ & $61(4.4)$ & $228(2.0)$ & $2.2(1.7-3.0)$ & $2.1(1.5-2.8)$ \\
\hline 6-10yrs & $28(5.9)$ & $109(3.2)$ & $1.9(1.2-2.9)$ & $1.7(1.1-2.6)$ \\
\hline \multicolumn{5}{|c|}{ Nervous system diseases } \\
\hline $0-12$ months & $38(1.5)$ & $39(0.2)$ & $9.9(6.3-15.5)$ & $9.7(6.0-15.7)$ \\
\hline $13 \mathrm{mths}-2 \mathrm{yrs}$ & $13(0.6)$ & $35(0.2)$ & $3.5(1.8-6.6)$ & $2.4(1.2-4.6)$ \\
\hline $3-5 y r s$ & $13(0.9)$ & $42(0.4)$ & $2.6(1.4-4.8)$ & $2.4(1.2-4.6)$ \\
\hline 6-10yrs & $18(3.7)$ & $22(0.6)$ & $6.0(3.2-11.3)$ & $5.6(2.8-11.0)$ \\
\hline \multicolumn{5}{|c|}{ Cardiovascular diseases } \\
\hline $0-12$ months & $96(3.9)$ & $681(2.8)$ & $1.4(1.1-1.8)$ & $1.4(1.1-1.7)$ \\
\hline $13 \mathrm{mths}-2 \mathrm{yrs}$ & $71(3.3)$ & $559(2.8)$ & $1.2(0.9-1.5)$ & $1.1(0.8-1.4)$ \\
\hline $3-5 y r s$ & $125(9.1)$ & $827(7.2)$ & $1.3(1.1-1.5)$ & $1.2(0.9-1.5)$ \\
\hline 6-10yrs & $71(14.7)$ & $337(9.8)$ & $1.6(1.2-2.1)$ & $1.4(1.1-1.9)$ \\
\hline \multicolumn{5}{|l|}{ Digestive diseases } \\
\hline $0-12$ months & $68(2.7)$ & $63(0.3)$ & $11.1(7.8-15.7)$ & $11.9(8.3-17.2)$ \\
\hline $13 \mathrm{mths}-2 \mathrm{yrs}$ & $21(0.9)$ & $49(0.2)$ & $4.0(2.4-6.8)$ & $3.3(1.9-5.7)$ \\
\hline $3-5 y r s$ & $23(1.7)$ & $67(0.6)$ & $2.9(1.8-4.6)$ & $2.9(1.8-4.9)$ \\
\hline 6-10yrs & $8(1.7)$ & $29(0.8)$ & $1.9(0.9-4.3)$ & $1.7(0.8-4.0)$ \\
\hline \multicolumn{5}{|l|}{ Unintentional injuries } \\
\hline $0-12$ months & $198(7.9)$ & $525(2.1)$ & $4.0(3.4-4.8)$ & $3.9(3.2-4.6)$ \\
\hline $13 \mathrm{mths}-2 \mathrm{yrs}$ & $124(5.8)$ & $418(2.1)$ & $2.9(2.4-3.5)$ & $2.7(2.2-3.3)$ \\
\hline $3-5 y r s$ & $148(10.7)$ & $701(6.1)$ & $1.8(1.5-2.2)$ & $1.8(1.5-2.2)$ \\
\hline $6-10 y r s$ & $94(19.5)$ & $297(8.7)$ & $2.5(1.9-3.3)$ & $2.6(2.0-3.4)$ \\
\hline \multicolumn{5}{|c|}{ Intentional injury/self-harm } \\
\hline $0-12$ months & $29(1.2)$ & $73(0.3)$ & $4.0(2.6-6.2)$ & $3.0(1.9-4.7)$ \\
\hline $13 \mathrm{mths}-2 \mathrm{yrs}$ & $40(1.9)$ & $53(0.3)$ & $7.2(4.8-10.9)$ & $5.9(3.8-9.0)$ \\
\hline $3-5 y r s$ & $50(3.6)$ & $55(0.5)$ & $7.8(5.3-11.5)$ & $6.3(4.2-9.6)$ \\
\hline $6-10 y r s$ & $32(6.6)$ & $32(0.9)$ & $7.6(4.6-12.5)$ & $6.8(3.9-11.7)$ \\
\hline
\end{tabular}

\begin{tabular}{|c|c|c|}
\hline \multicolumn{3}{|c|}{ Numbers at risk within each analyses time period } \\
\hline 0-12months & $2,479(100.0)$ & $24,790(100.0)$ \\
\hline 13months-2years & $2,151(86.8)$ & $20,162(81.3)$ \\
\hline 3-5years & $1,377(55.6)$ & $11,422(46.1)$ \\
\hline 6-10years & $482(19.4)$ & $3,432(13.8)$ \\
\hline
\end{tabular}

\footnotetext{
*Adjustment for age, sex and smoking status

- number within cell <5
} 